Article

\title{
High-Throughput Screening Identified Compounds Sensitizing Tumor Cells to Glucose Starvation in Culture and VEGF Inhibitors In Vivo
}

\author{
Ran Marciano ${ }^{1,2, \dagger}$, Manu Prasad ${ }^{3, \dagger}$, Tal Ievy ${ }^{1}$, Sapir Tzadok ${ }^{3}$, Gabriel Leprivier ${ }^{4}$, \\ Moshe Elkabets ${ }^{3, *(\mathbb{D})}$ and Barak Rotblat $1,2, *$ (D) \\ 1 Department of Life Sciences, Ben-Gurion University of the Negev, Beer Sheva 84105, Israel; \\ ranmarci@post.bgu.ac.il (R.M.); levyag@post.bgu.ac.il (T.I.) \\ 2 The National Institute for Biotechnology in the Negev, Beer Sheva 84105, Israel \\ 3 The Shraga Segal Department of Microbiology, Immunology and Genetics, Faculty of Health Sciences, \\ Ben-Gurion University of the Negev, Beer-Sheva 84105, Israel; mpmnedumudy@gmail.com (M.P.); \\ sapirtza@post.bgu.ac.il (S.T.) \\ 4 Department of Pediatric Oncology, Hematology, and Clinical Immunology, Medical Faculty, \\ University Hospital Düsseldorf, 40225 Düsseldorf, Germany; gabriel.leprivier@med.uni-duesseldorf.de \\ * Correspondence: moshee@bgu.ac.il (M.E.); rotblat@bgu.ac.il (B.R.); \\ Tel.: +972-8-6428-846 (M.E.); +972-8-6428-806 (B.R.) \\ + These authors contributed equally to the work.
}

Received: 27 December 2018; Accepted: 28 January 2019; Published: 30 January 2019

\begin{abstract}
Tumor cells utilize glucose to fuel their anabolic needs, including rapid proliferation. However, due to defective vasculature and increased glucose uptake, tumor cells must overcome glucose deprivation. Accordingly, tumor cells depend on cellular pathways promoting survival under such conditions. Targeting these survival mechanisms can thus serve as a new therapeutic strategy in oncology. As such, we sought to identify small-molecule inhibitors which sensitize tumor cells to glucose starvation by high-throughput drug screening in vitro. Specifically, we searched for inhibitors that selectively killed tumor cells growing in glucose-free but not in normal medium. This phenotypic drug screen of 7000 agents with MCF7 cells led to the identification of 67 potential candidates, 31 of which were validated individually. Among the identified compounds, we found a high number of compounds known to target mitochondria. The efficacies of two of the identified compounds, QNZ (EVP4593) and papaverine, were validated in four different tumor cell lines. We found that these agents inhibited the mTOR(Mechamistic \Mammilian Target of Rapamycin) pathway in tumor cells growing under glucose starvation, but not under normal conditions. The results were validated and confirmed in vivo, with QNZ and papaverine exhibiting superior antitumor activity in a tumor xenograft model when combined with the VEGF inhibitor bevacizumab (avastin). Administering these drug combinations (i.e., avastin and papaverine, and avastin and QNZ) led to significant reductions in proliferation and mTOR activity of the aggressive DLD1 colon cell line in mice. Given our findings, we propose that compounds targeting metabolically challenged tumors, such as inhibitors of mitochondrial activity, be considered as a therapeutic strategy in cancer.
\end{abstract}

Keywords: cancer metabolism; drug combination; synthetic lethality; HTS; small molecule

\section{Introduction}

Tumor cells upregulate glucose metabolism and oxidative phosphorylation (OXPHOS) to support their enhanced anabolic demands [1,2]. Apart from glycolysis, glucose is also utilized by the pentose phosphate pathway, the hexosamine pathway, and the one-carbon metabolism pathway to generate 
building blocks and reducing power for the cell [1]. Indeed, glucose uptake is upregulated by various oncogenes, such as MYC [3] and RAS [4], with such tumor-driven high glucose uptake being exploited for diagnosis using radiolabelled glucose analogues such as ${ }^{18} \mathrm{~F}-\mathrm{FDG}$ and positron emission tomography. However, a number of tumors develop within a glucose-depleted tumor microenvironment [4-8], as measurements of glucose levels in tumor tissues indicate a 2-45-fold reduction in glucose in such tumors compared to normal surrounding tissues $[9,10]$. Hence, these tumor cells must evolve proper cellular mechanisms to adapt to low-glucose conditions.

In an unbiased shRNA-based (short hairpin RNA) screen targeting metabolic proteins specifically aimed at identifying proteins that support the survival of tumor cells in low-glucose-containing medium, Birsoy et al. identified mitochondrial OXPHOS proteins, and in particular, complex I proteins, as being central for the metabolic adaptation of tumor cells to low-glucose conditions [9]. In addition, other studies have identified several protective cellular pathways supporting the survival of tumor cells growing in glucose deprivation, including the unfolded protein response (UPR) pathway [11], the mTOR pathway [12-16], and the NF-kB pathway [17].

These requirements support the premise that proteins and cellular pathways which support cell survival under glucose starvation represent potential drug targets, as their inhibition is expected to selectively kill glucose-depleted tumor cells, but not normal tissues that do not experience glucose deprivation $[9,18]$.

Based on the observations described above, we performed a phenotypic synthetic lethality high-throughput (HTP) drug screen in the hope of finding new potential anticancer drugs. In doing so, we identified compounds which selectively kill tumor cells growing in glucose-free media. Strikingly, we found significant enrichment for mitochondrial poisons. We validated the activity of two such compounds, QNZ (EVP4593) and papaverine, in culture and demonstrated that a combination of the antiangiogenic agent bevacizumab with QNZ or papaverine had superior antitumor activity in vivo than shown by either agent alone. These findings support the concept that pharmacological targeting of glucose-deprived tumor cells in vitro has the power to uncover compounds that can act synergistically with antiangiogenic agents to inhibit tumor growth in vivo.

\section{Materials and Methods}

\subsection{Cell Cultures}

DLD, MCF7, PANC1, H1299, and U87 cells were cultured in Dulbecco's modified Eagle's medium (DMEM) (Biological Industries, Kibbutz Beit-Haemek, Israel) containing antibiotic-antimycotic (Tivan Biotech, Kfar-Saba, Israel), $1 \mathrm{mM}$ sodium pyruvate, and 10\% fetal bovine serum (FBS) (Biological Industries). All cell cultures were incubated in $5 \% \mathrm{CO}_{2}$ at $37^{\circ} \mathrm{C}$. For glucose starvation, the medium was replaced with glucose-free DMEM containing antibiotic-antimycotic and $10 \%$ FBS.

\subsection{Cell Viability Assays}

For compound screening, cells were plated on 384-well plates containing one compound/vehicle per well with or without glucose in the medium. The plates were incubated in $5 \% \mathrm{CO}_{2}$ at $37^{\circ} \mathrm{C}$ for $48 \mathrm{~h}$. Cell viability was measured using a CellTiter-Glo Luminescent Cell Viability Assay kit (Promega, Madison, WI, USA). For validation of compound screening and determination of the $\mathrm{IC}_{50}$ values, cells were plated in 24-well plates with glucose-depleted medium and the compound of interest. The plates were incubated in $5 \% \mathrm{CO}_{2}$ at $37^{\circ} \mathrm{C}$ for $48 \mathrm{~h}$, followed by aspirating the medium and washing with PBS. Two hundred and fifty microliters of crystal violet staining solution $(0.5 \%(\mathrm{w} / \mathrm{v})$ crystal violet powder, 20\% methanol) was added to the plates. After incubation for $10 \mathrm{~min}$ at room temperature, the staining solution was discarded, the plates were washed 5 times with distilled water and dried, and $250 \mu \mathrm{L}$ of $10 \%$ acetic acid was added to each well. Absorbance was measured at $570 \mathrm{~nm}$. 


\subsection{Cell Death Assays}

Cell death was determined using flow cytometry. Cells were harvested at $48 \mathrm{~h}$ post-treatments and stained with annexin V/PI using an apoptosis detection kit (Miltenyi Biotec, Bergisch Gladbach, Germany). Cells were analyzed using a flow cytometer (Sysmex, Kobe, Japan) equipped with FCS Express software according to the manufacturer's instructions.

\subsection{Cell Lysis and Sample Preparation}

Cell lysis was performed on ice. Cells were washed one time with PBS and scraped with RIPA lysis buffer $(150 \mathrm{mM} \mathrm{NaCl} ; 50 \mathrm{mM}$ Tris $\mathrm{pH}=8.0 ; 1 \%$ Triton $\mathrm{X}-100 ; 0.5 \%$ sodium deoxycholate; $0.1 \%$ SDS). Samples were sonicated and centrifuged at $4{ }^{\circ} \mathrm{C}$ for $20 \mathrm{~min}$. The supernatant was collected and stored at $-20^{\circ} \mathrm{C}$. Before proceeding, protein amounts were quantified using a Pierce ${ }^{\mathrm{TM}} \mathrm{BCA}$ Protein Assay Kit (Thermo Scientific, Waltham, MA, USA).

\subsection{Gel Electrophoresis and Immunoblotting}

Protein lysates were mixed with $5 \times$ sample loading buffer $(250 \mathrm{mM}$ Tris- $\mathrm{HCl} \mathrm{pH} 6.8 ; 10 \%$ SDS; $30 \%$ glycerol; $10 \mathrm{mM} \mathrm{DTT;} 0.05 \%$ (w/v) bromophenol blue), followed by $10 \mathrm{~min}$ at $96^{\circ} \mathrm{C}$ and spin-down. Samples were then loaded onto SDS-PAGE gels and gels were transferred on a nitrocellulose membrane. Membranes were blocked with blocking solution (5\% skim milk; Tris buffer saline (TBS)) for $1 \mathrm{~h}$. Membranes were incubated with primary antibody solution for $1 \mathrm{~h}$ at room temperature or overnight at $4{ }^{\circ} \mathrm{C}$, followed by washing with TBS. Membranes were incubated with secondary antibodies for $1 \mathrm{~h}$ at room temperature. Images were developed using the Western blotting Serius HRP substrate kit and an electrochemiluminescence imager (Thermo Scientific, Waltham, MA, USA) and processed using GIMP 2.8 software.

\subsection{Antibodies}

HSC70 antibody (sc-7298) was obtained from Santa Cruz. Antibodies for phospho-p70S6K (Thr389) (9206s), total p70S6K (2708s), total 4EBP1 (C-9644S), phospho-S6RP (Ser240/244) (2215S), phospho-4EBP1 (Ser65) (9451S), and anti-rabbit (C-7074S) and anti-mouse (C-7076S) phosphor-AKT (Ser473) (9271S) were obtained from Cell Signaling Technology (Danvers, MA, USA).

\subsection{Tumor Xenografts and Drug Treatments in Vivo}

For the xenograft experiments, 6-week-old NOD-SCID (NOD.CB17-Prkdc ${ }^{\text {scid }} / \mathrm{NCrCrl}$ ) mice were injected subcutaneously in the flank with DLD1 cells $\left(5 \times 10^{6}\right.$ cells per injection in PBS). Two independent experiments were performed and each experiment consisted of 20 mice. All mice developed tumors. When the tumor volume reached $150-200 \mathrm{~mm}^{3}$, they were randomized into four groups of five mice in each experiment. Animals were treated with vehicle (PBS/saline), papaverine (10 mg/kg), or QNZ (EVP4593) (1 mg/kg) daily via intraperitoneal injection, or bevacizumab $(5 \mathrm{mg} / \mathrm{kg})$ twice weekly in combination with papaverine $(10 \mathrm{mg} / \mathrm{kg})$ or QNZ $(1 \mathrm{mg} / \mathrm{kg})$. Tumors were measured with digital caliper twice a week, and tumor volumes were determined using the formula: length $\times$ width ${ }^{2} \times \pi / 6$. At the end of the experiment, animals were sacrificed using $\mathrm{CO}_{2}$ inhalation and the tumors were harvested for investigation. Tumor volumes were normalized to initial volumes and presented as an averaged percentage of the initial volumes \pm standard error of the mean (SEM).

Mice were maintained and treated according to the institutional guidelines of Ben-Gurion University of the Negev. Mice were housed in air-filtered laminar flow cabinets with a 12-h light/dark cycle and food and water ad libitum. Animal experiments were approved by the Ben Gurion University of the Negev animal care and use committee (license number: IL.80-12-2015).

\subsection{Immunohistochemistry (IHC) and Analysis}

Following mice sacrifice, tumors were fixed in $4 \%$ paraformaldehyde. Tissues were dehydrated using alcohol gradient and embedded in paraffin. Five-micrometer sections were taken, deparaffinized, 
and dehydrated using xylene and alcohol gradients, respectively. The slides were incubated in $10 \mathrm{mM}$ citric acid buffer, $\mathrm{pH} 6.0$ at $100{ }^{\circ} \mathrm{C}$ for $20 \mathrm{~min}$ for antigen retrieval. The endogenous peroxidase activity was blocked with $\mathrm{H}_{2} \mathrm{O}_{2}(0.3 \%)$. Sections were then blocked for $1 \mathrm{~h}$ at room temperature with blocking solution (PBS, 0.1\% TWEEN, 5\% BSA), followed by incubation with primary antibodies. Ki67 (275R-1, Sigma, St. Louis, MO, USA), pS6RP (4857S, Cell Signaling, Danvers, MA, USA), and CD31 (ab28364, Abcam, Cambridge, UK) antibodies were diluted in blocking solution and incubated overnight at $4{ }^{\circ} \mathrm{C}$. The ABC kit (VECTASTAIN Cat. VE-PK-6200) was used for detection according to the manufacturer's protocol. Sections were counterstained with hematoxylin, dehydrated, and mounted with mounting media (Micromount, Leica, Cat. 380-1730, Wetzlar, Germany). IHC slides were digitalized using the Pannoramic Scanner (3DHISTECH, Budapest, Hungary) and analyzed using QuantCenter (3DHISTECH) using a single threshold parameter for all images of a specific staining sample in each experiment.

\subsection{Statistics}

Statistical analyses were done using GraphPad Prism 7.03 software. All cellular experiments were repeated at least three times. A two-tailed Student's unpaired $t$ test was performed to compare control versus treated group. $p$ values of $0.05\left(^{*}\right), 0.01\left(^{* *}\right)$, and $0.001\left(^{* * *}\right)$ were considered statistically significant. For experiments with more than two groups, a one-way ANOVA was calculated using Turkey's multiple comparison test. In vivo experiments were performed with indicated $\mathrm{n}$ values, and a one-way ANOVA test was performed to compare between groups.

\section{Results}

\subsection{High-Throughput Synthetic Lethality Drug Screening for Selectively Potent Compounds under} Glucose Starvation

To identify compounds specifically targeting tumor cells under glucose starvation conditions, we employed a strategy whereby cells were directly seeded in glucose-free or normal medium in 384-well plates containing the library of compounds being tested. This allowed the cells to grow for a given amount of time, after which cell viability was measured. Viability was compared between cells growing either in glucose-free or glucose-proficient medium in parallel plates (the workflow scheme is shown in Figure 1A). Any compound significantly reducing viability under glucose starvation but not in normal medium was considered a positive hit (depicted in yellow in Figure 1A).

To set up the high troughput screen (HTP), we initially tested several conditions to determine the optimal number of cells for plating and time of treatment before measuring viability (Figure 1B). Specifically, we subjected the breast tumor cell line MCF7 to a 48-h period of treatment based on the evidence that glucose deprivation did not affect MCF7 viability when plated at 2000 cells/well within the first $48 \mathrm{~h}$. Viability, however, dropped $72 \mathrm{~h}$ post-treatment (Figure 1B). Because MCF7 cells are fully viable after $48 \mathrm{~h}$ under glucose-starved conditions, any significant reduction in viability induced by a given compound at this time point would be indicative of it being a potential positive hit (Figure 1A).

Using these conditions, we screened 7000 compounds (Selleckchem, Munich, Germany). Upon plotting cell viability in normal versus glucose-free medium, we identified 67 compounds (Supplementary Table S1) which significantly reduced viability in glucose-free but not in normal medium (Figure 1C). Therefore, the HTP strategy employed here allowed us to identify compounds specifically targeting glucose-deprived tumor cells. 
A count cells
seed cells
into plates with
compounds
grow cells for
48 hours
measure
viability

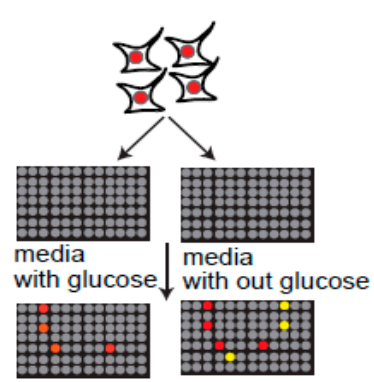

C
B

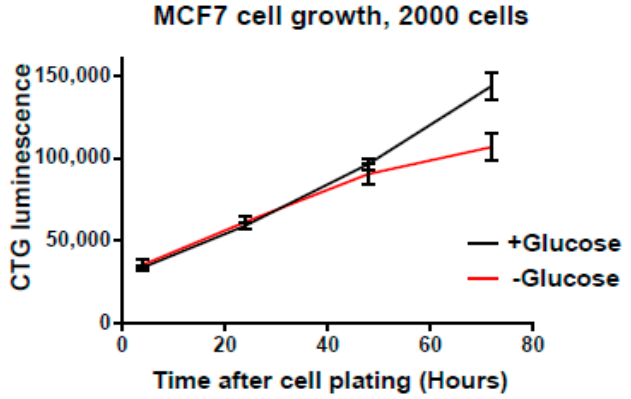

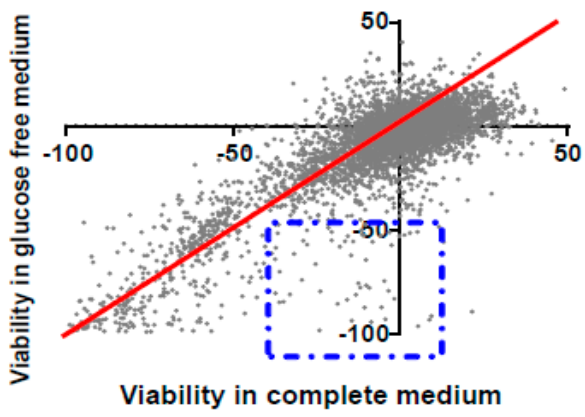

Figure 1. Highthroughput (HTP) screen for compounds selectively targeting cell viability under glucose starvation. (A) HTP drug screen pipeline. MCF7 cells were plated in glucose-free or normal medium in 384-well plates containing members of a compound library. Cell viability was measured after a given amount of time, and viability in glucose-free medium was compared with viability in normal medium. A positive hit was scored for compounds selectively reducing viability under glucose starvation. (B) Calibration of conditions used for HTP drug screening. At the indicated time points, the viability of MCF7 cells grown under glucose depletion was measured using a Cell-Titer-Glow kit (CTG). (C) HTP screening results. The viability of cells in normal and glucose-free media was plotted. Compounds exhibiting reduced viability under glucose starvation, as compared with normal conditions, are boxed.

\subsection{Screen Validation and Identification of QNZ and Papaverine as Compounds with Selective Toxicity under Glucose Starvation}

We next validated the 67 identified compounds in terms of selectivity for glucose-deprived conditions by determining the half-maximal inhibitory concentration $\left(\mathrm{IC}_{50}\right)$ for $\mathrm{MCF} 7$ cells grown in normal or glucose-free medium. Such analysis revealed that 31 compounds were significantly more toxic under glucose starvation conditions, as compared with growth in normal medium (Figure 2A; Supplementary Table S2). Strikingly, we found that $\sim 50 \%$ of the positive hits corresponded to known mitochondrial toxins (Figure 2B; Supplementary Table S2). Our findings thus reinforce previous reports showing that cells are dependent on optimal mitochondrial activity to survive glucose starvation $[9,19,20]$.

We further confirmed these findings in three tumor cell lines using two selected drugs, QNZ and papaverine, both known to inhibit mitochondrial activity [21,22]. The three tumor cells lines, namely the DLD1 (colon cancer), MCF7 (breast cancer), and U87 (brain cancer) cell lines, were cultured in glucose-containing or glucose-free medium, and viability was measured after applying increasing concentrations of QNZ and papaverine. Using this approach, we determined the $\mathrm{IC}_{50}$ of $\mathrm{QNZ}$ or papaverine on each cell line grown in glucose-free and normal media, and found that the efficacy of both agents was dependent on glucose levels (Figure $2 \mathrm{~B}$ ). Indeed, the $\mathrm{IC}_{50}$ for $\mathrm{QNZ}$ was calculated to be $\sim 3 \mathrm{nM}$ under glucose-deprived conditions, but could not be calculated under normal conditions (Figure 2B). Similarly, papaverine exhibited an $\mathrm{IC}_{50}$ of $\sim 3 \mu \mathrm{M}$ in glucose-free medium and $<10 \mu \mathrm{M}$ under normal conditions (Figure 2B). 
A

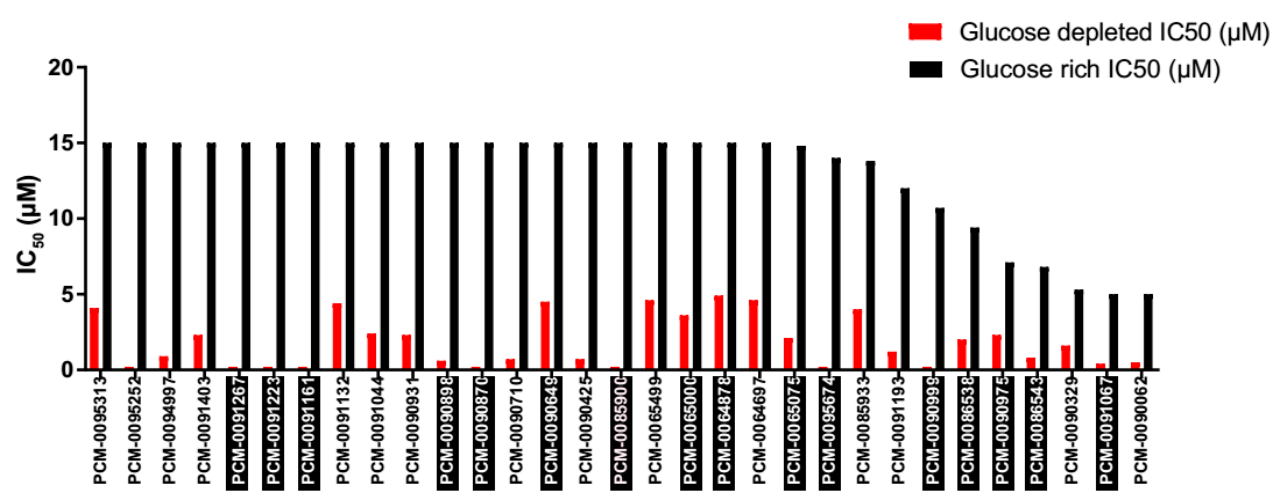

B

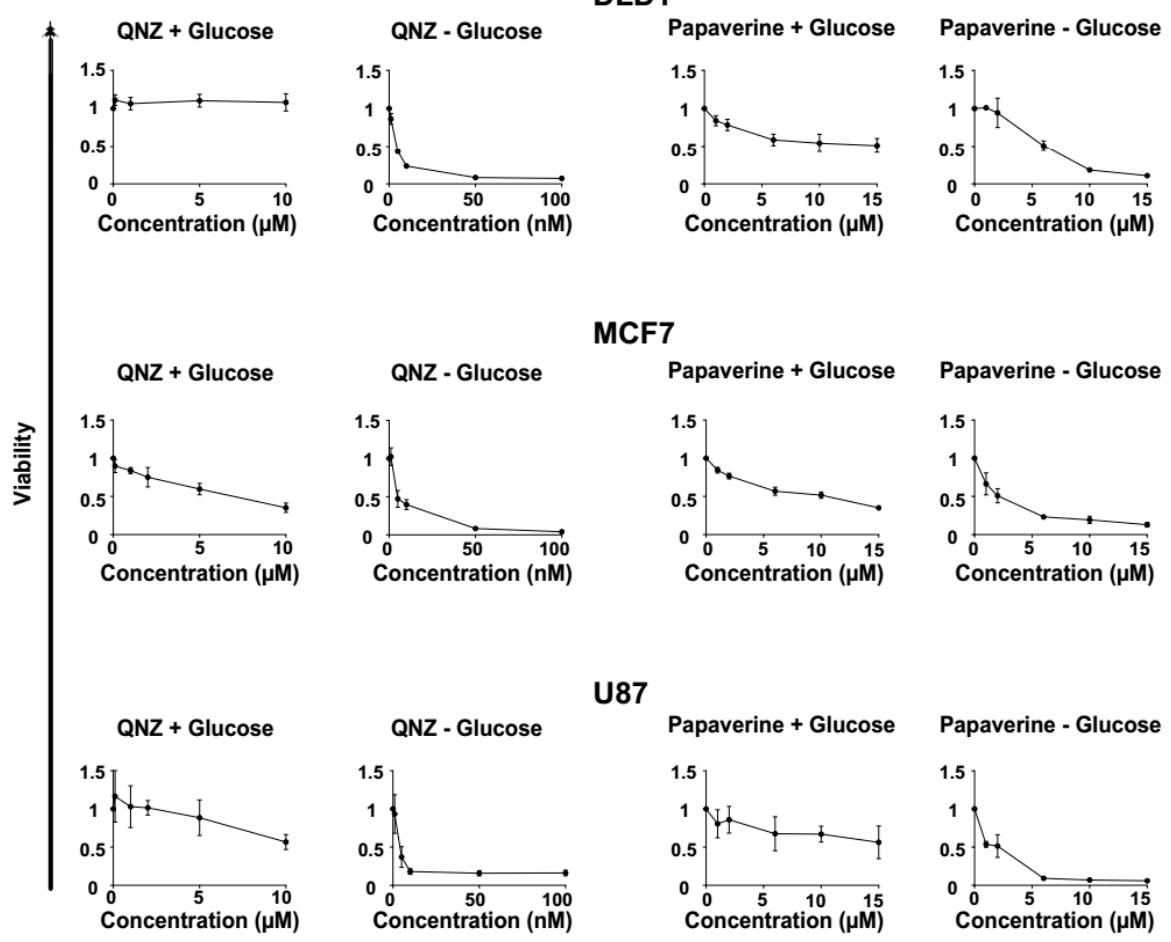

Figure 2. $\mathrm{IC}_{50}$ of the identified compound hits. (A) $\mathrm{IC}_{50}$ values of the 31 best hits were determined using a Cell-Titer-Glo kit. Compounds with black background are known to be mitochondrial poisons. (B) $\mathrm{IC}_{50}$ values of QNZ or papaverine with DLD1, MCF7 and U87 cells under the indicated conditions were determined using crystal violet staining. Data represents means $\pm \mathrm{SD} ;{ }^{*} p<0.05 ; \mathrm{n} \geq 3$ independent experiments.

For further validation, we retested the compounds QNZ and papaverine using DLD1 and U87 cells under glucose starvation and normal conditions, as well as two additional cell lines, i.e., the H1299 (lung cancer) and PANC1 (pancreatic cancer) lines (Figure 3A). We found that in all cases, tumor cells treated with QNZ or papaverine exhibited a greater reduction in viability under glucose starvation than when grown in glucose-proficient medium.

Given that reduction in cell viability can result from increased cell death, we assessed the impact of QNZ and papaverine on cell death. Accordingly, we treated DLD1, MCF7, and U87 cells with QNZ or papaverine in the presence or absence of glucose in the medium and measured rates of cell death $48 \mathrm{~h}$ post-treatment using annexin V/PI staining and flow cytometry (Figure 3B). As expected, we detected extensive staining for annexin V in tumor cells treated with QNZ or papaverine upon glucose starvation, but not under normal conditions, indicating that these compounds specifically induced 
apoptosis under these restricted conditions. Together, these data indicate that QNZ and papaverine selectively kill tumor cells subjected to glucose deprivation.

A
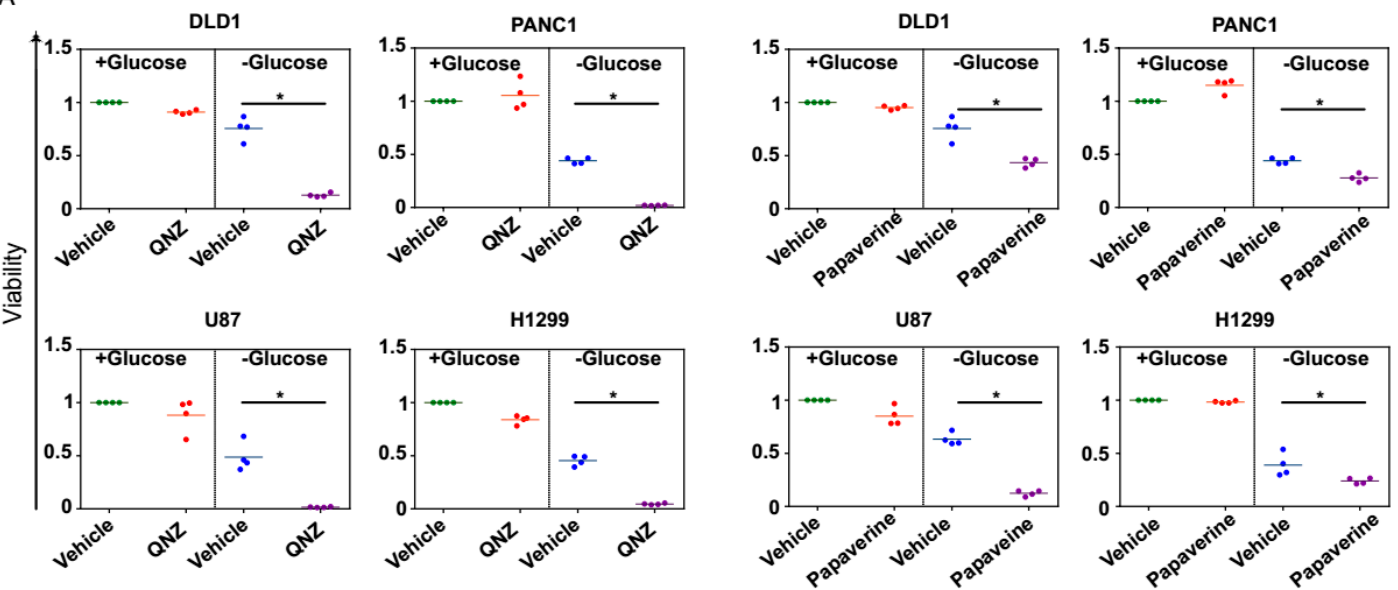

B
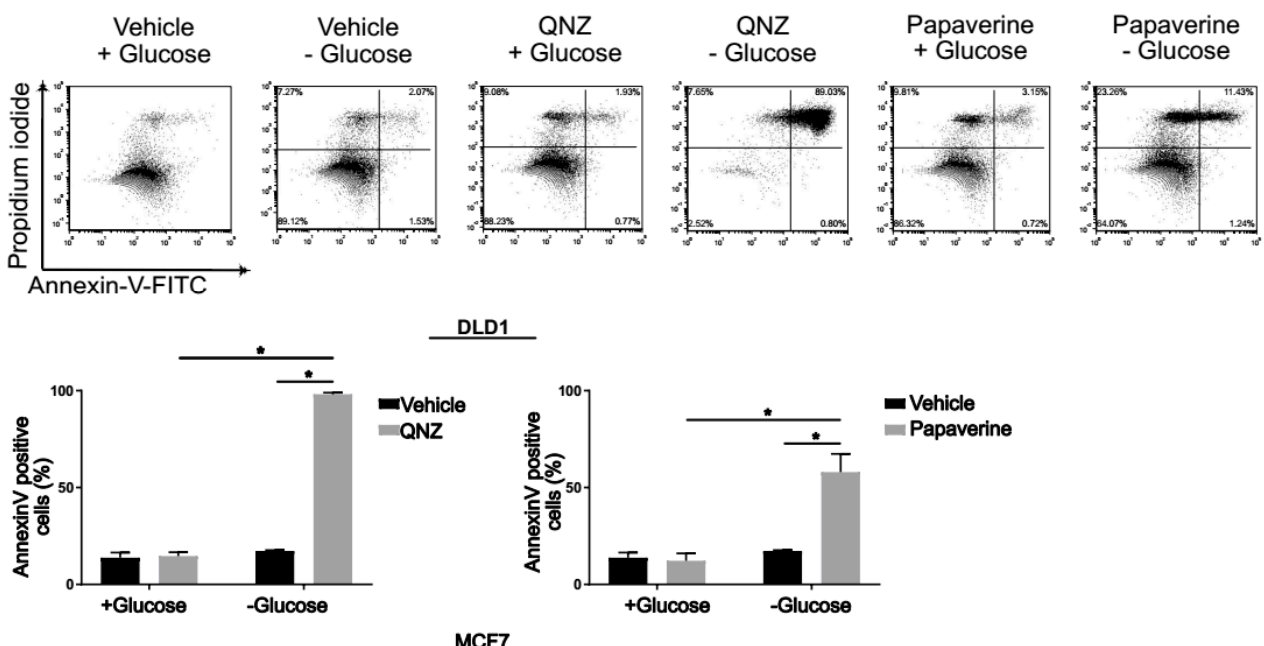

MCF7
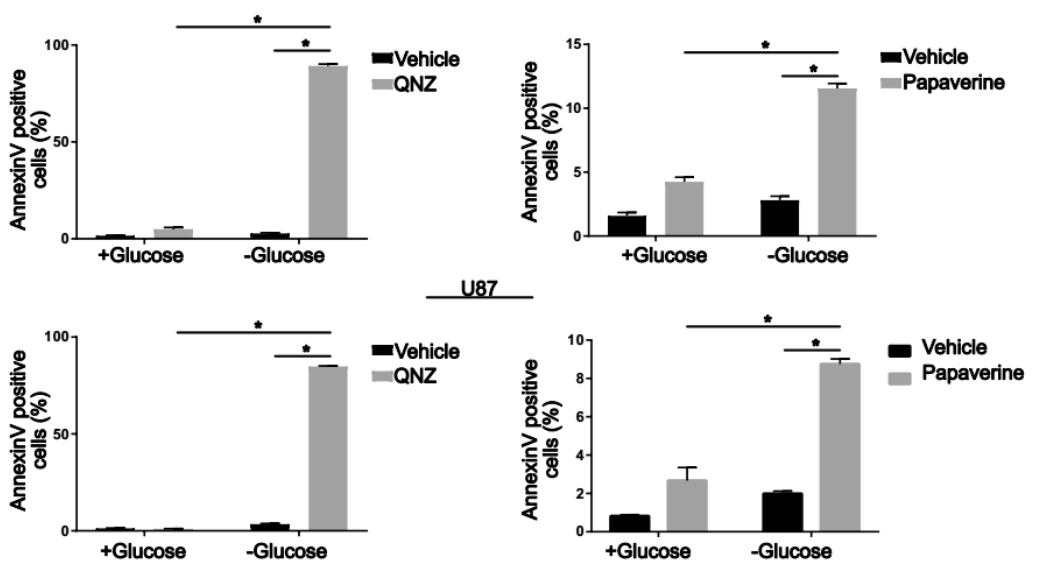

Figure 3. Selective killing of tumor cells under glucose starvation by QNZ and papaverine. (A) The viability of four tumor cell lines treated with QNZ $(100 \mathrm{nM})$ or papaverine $(3 \mu \mathrm{M})$ for $48 \mathrm{~h}$ under glucose starvation and normal conditions was determined using crystal violet staining. ${ }^{*} p<0.05$. (B). Cell death of cells treated with the indicated compounds for $24 \mathrm{~h}$ in normal or glucose-starved medium was measured by annexin V/ Propidium iodide (PI) staining and fluorescence-activated cell sorting (FACS). Typical FACS plots obtained using MCF7 cells are shown. Data represent mean \pm SD; ${ }^{*} p<0.05 ; \mathrm{n} \geq 3$ independent experiments. 


\subsection{QNZ and Papaverine Inhibit the mTOR Pathway Selectively under Glucose Starvation}

To obtain further molecular insight into the cellular response to QNZ and papaverine under glucose-starved conditions, we analyzed the activity of the mTOR pathway, which is a master regulator of the response to glucose starvation [12-16]. For this, DLD1, MCF7, and U87 cells treated with or without QNZ or papaverine in normal or glucose-free medium were analyzed for levels of phosphorylated-4EBP1, phosphorylated-P70S6K, and phosphorylated-S6RP, all reflective of mTOR pathway activity $[23,24]$. While a 3-h period of glucose starvation did not reduce phospho-4EBP1, phospho-P70S6K, or phospho-S6RP levels, likely due to the short period of the glucose challenge, we found that treatment with QNZ or papaverine led to a striking reduction in phosphorylated protein levels under these conditions, indicating inhibition of the mTOR pathway (Figure 4A). In contrast, treatment with any of the compounds had no effect on the levels of phospho-4EBP1, phospho-P70S6K, and phospho-S6RP under normal conditions (Figure 4A). These data indicate that cells respond to the combination of either QNZ or papaverine with glucose starvation by inhibiting the mTOR pathway. Furthermore, the phosphorylation of AKT was variable between cell lines, glucose levels, and the compounds (Figure 4A), supporting the notion that the mTOR pathway is specifically affected by QNZ and papaverine under glucose starvation.

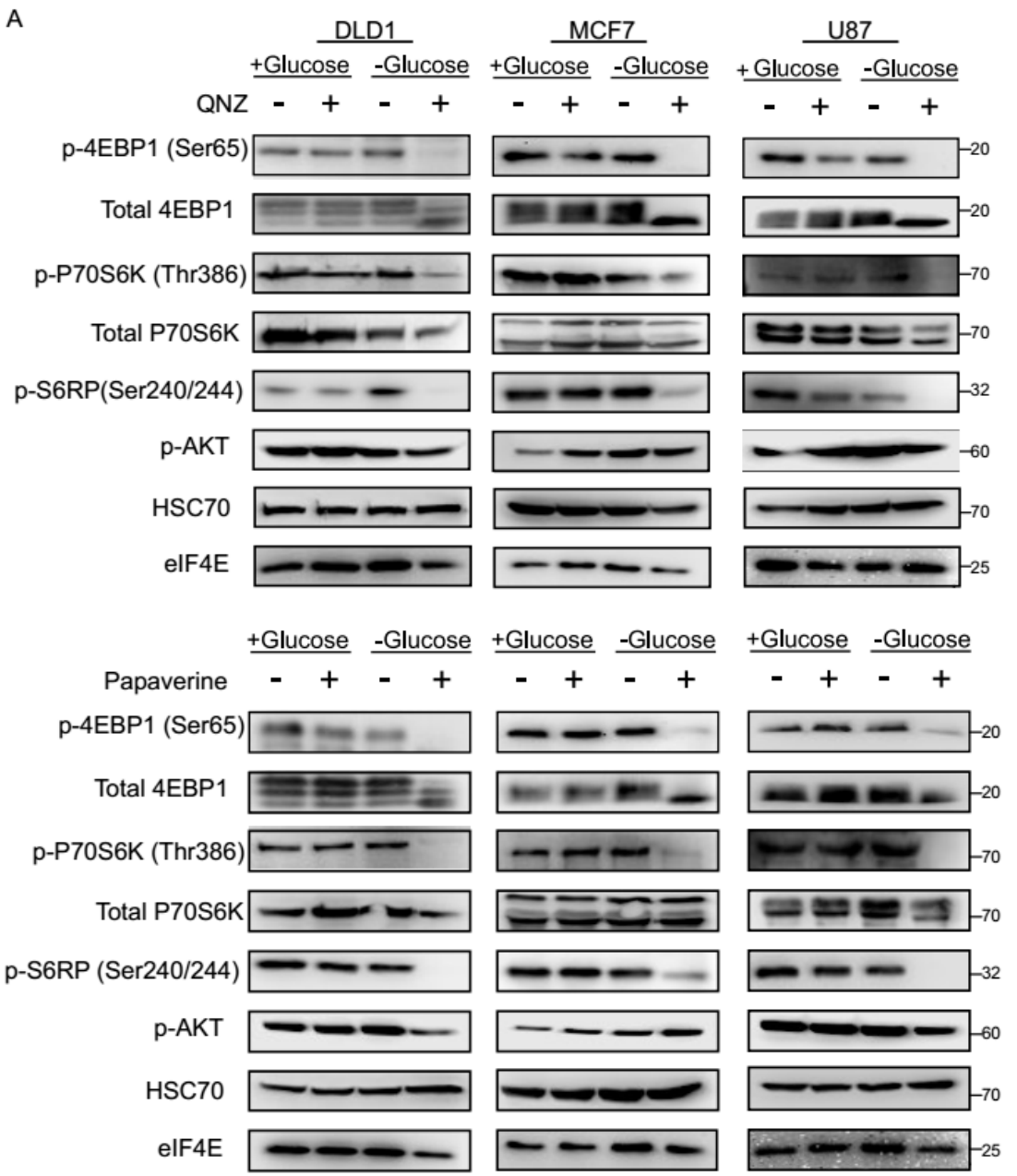

Figure 4. Cont. 
B
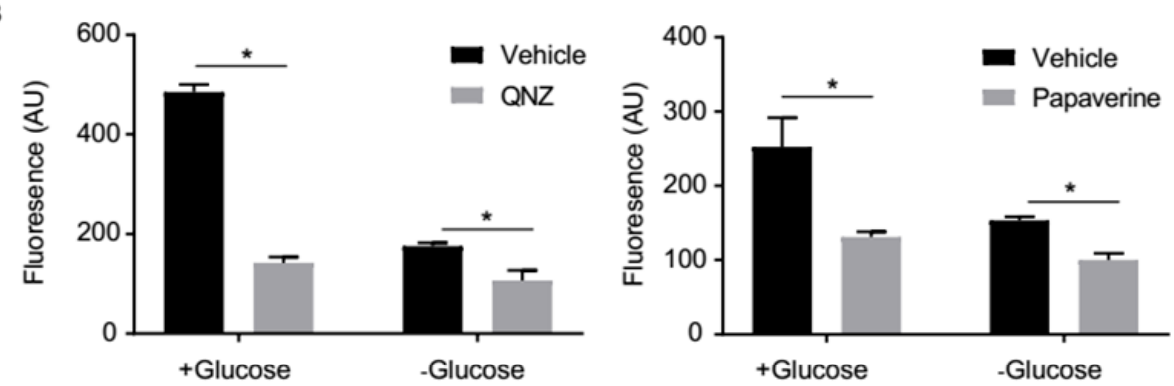

Figure 4. Acute inhibition of the mTOR pathway in tumor cells treated by papaverine and QNZ under glucose starvation. The indicated cells were treated for $3 \mathrm{~h}$ with papaverine $(10 \mu \mathrm{M})$ or QNZ $(100 \mathrm{nM})$ in the presence or absence of glucose, after which cell lysates were collected and analyzed by immunoblot using the indicated antibodies. (B) Mitochondrial activity of DLD1 cells treated as in (A) was measured by TMRE (Tetramethylrhodamine, ethyl ester) and FACS (fluorescence-activated cell sorting). AU = arbitarary units. Data represents mean $\pm \mathrm{SD} ;{ }^{*} p<0.05 ; \mathrm{n} \geq 3$ independent experiments.

We next explored if treatment of tumor cells with QNZ or papaverine affects mitochondrial activity under normal and glucose-starved conditions. Tetramethylrhodamine, ethyl ester (TMRE) and flow cytometry analysis showed that both QNZ and papaverine inhibited mitochondrial membrane potential regardless of whether the cells were glucose-starved or not (Figure 4B). The mitochondrial inhibitory activities of QNZ and papaverine are in accord with previous findings [21,22]. Because cells are dependent on mitochondrial activity for survival under glucose starvation, it is therefore likely that the selective toxicity of QNZ and papaverine towards glucose-starved cells is, at least in part, related to inhibition of mitochondrial activity.

\subsection{QNZ and Papaverine Enhance the Antitumor Activity of Bevacizumab in Vivo}

To evaluate the efficacy of QNZ and papaverine in targeting tumor development in vivo, we hypothesized that such compounds, which exhibit selective toxicity upon glucose starvation, would enhance the efficacy of drugs promoting metabolic stress in tumors. One such drug is the antiangiogenic bevacizumab (also known as avastin). To test our hypothesis, we established tumor xenografts in NOD-SCID mice using the aggressive DLD1 colon cancer cell line. When the tumors reached $100 \mathrm{~mm}^{3}$ in diameter, treatment was initiated. We followed tumor growth for 14 days, after which time the tumors were removed and their masses were measured. As shown in Figure 5A,B, the combination of QNZ or papaverine with bevacizumab, respectively, was significantly more potent than were the single agents, as reflecting by a slowing of tumor growth and the significantly less massive size of the tumors.

To further characterize the effect of our treatments on tumors, IHC analysis was performed. We found that the levels of the proliferation marker Ki-67 were lower in tumors treated with a combination of papaverine or QNZ and bevacizumab, as compared to the single agents alone. These results are in line with our findings that tumors subjected to combination treatments were smaller, as compared to those treated with papaverine or QNZ alone (Figure 5A,B). We also found that phosphorylated S6RP levels were lower in the tumors treated with the drug combination, as compared to treatment with single agents (Figure 5C,D), indicative of a reduction in mTOR pathway activity. These results are in line with our findings in cell culture, showing that when combined with glucose starvation, QNZ and papaverine inhibited the mTOR pathway (Figure 4A). Finally, we found significant reduction in the levels of CD31, a marker of endothelial cells, in all bevacizumab-treated tumors (Figure 5C,D), as would be expected from an antiangiogenic. This further supports our model, according to which, compounds with selective toxicity towards glucose-starved cells enhance the efficacy of drugs that induce metabolic stress in tumors in vivo. 

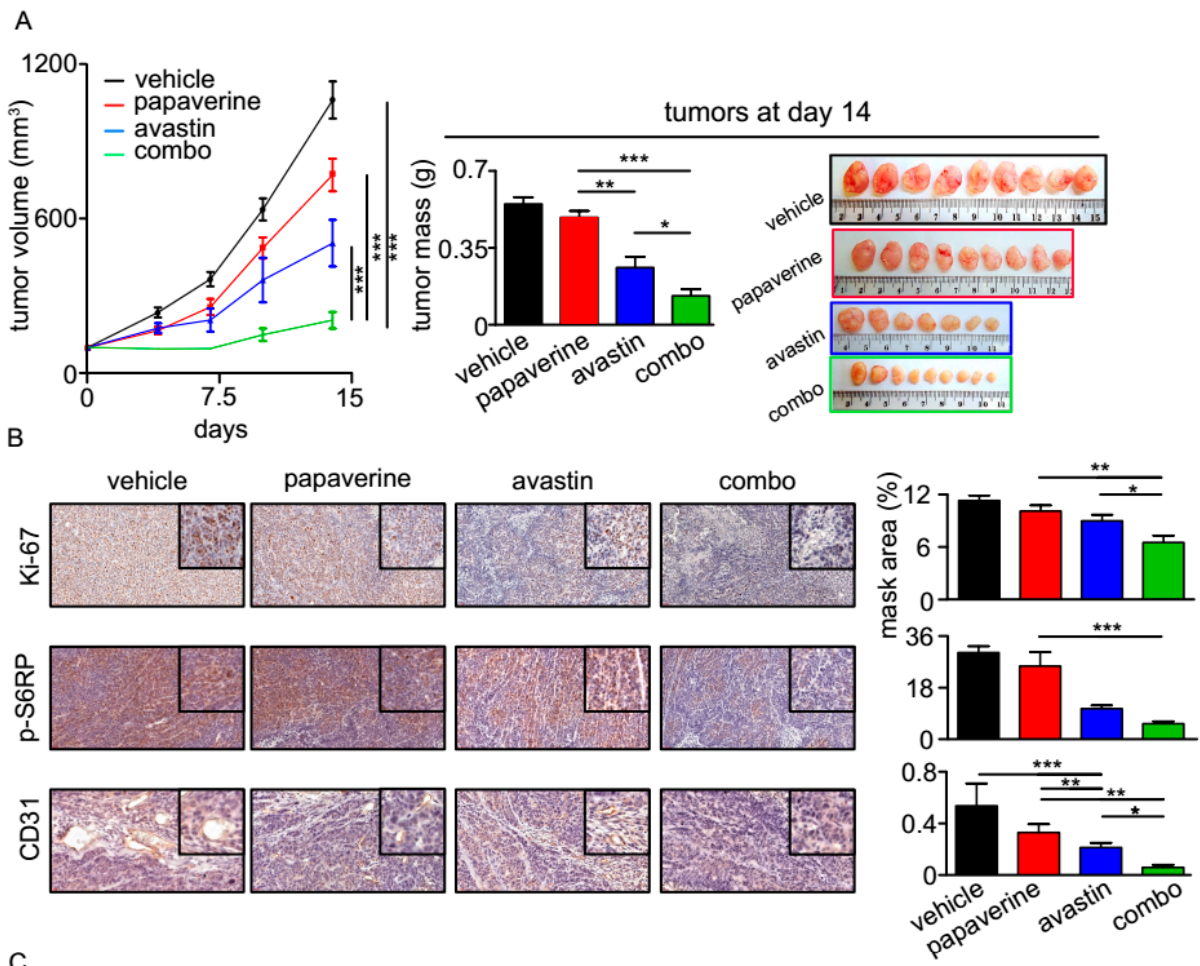

$c$
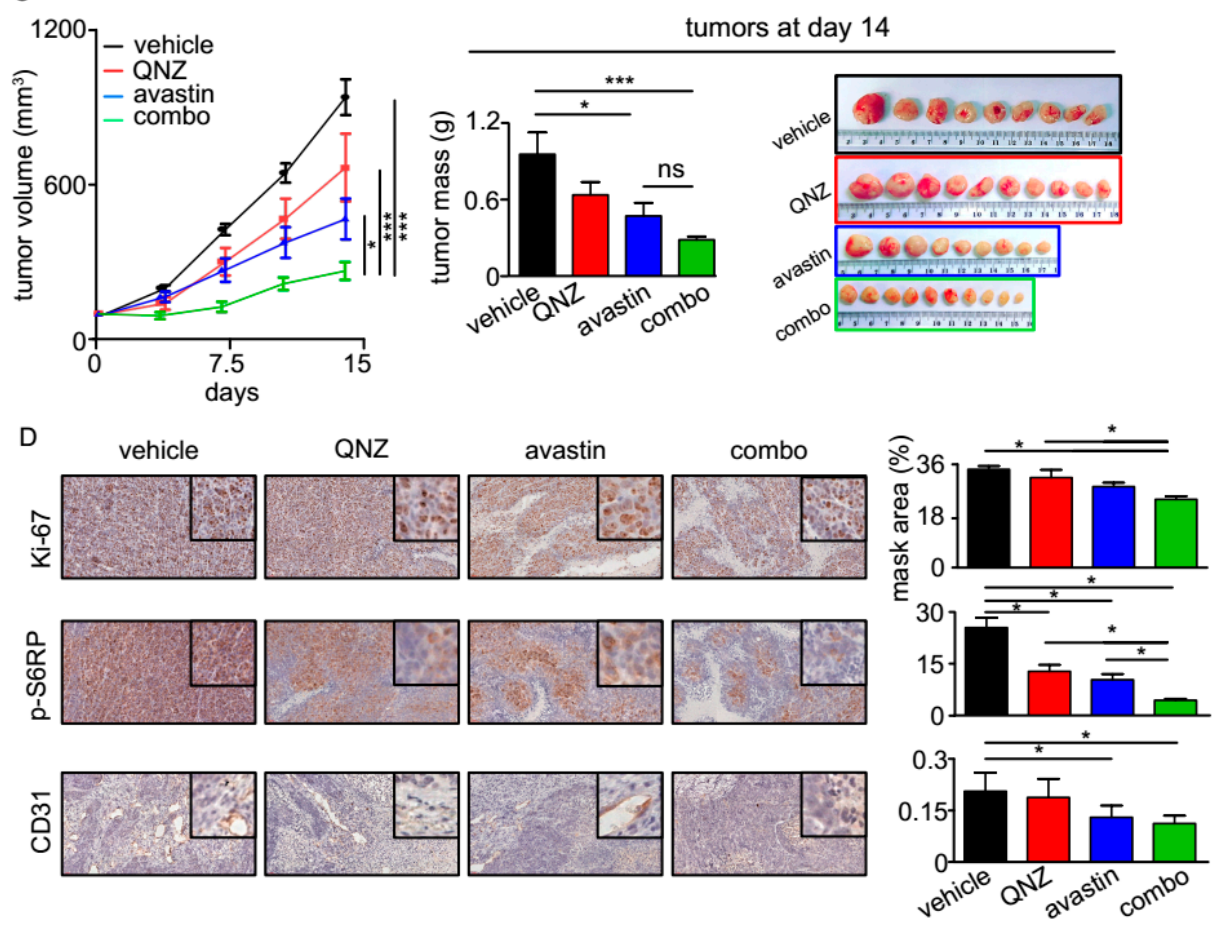

Figure 5. Combinations of bevacizumab with QNZ or papaverine delay tumor progression in vivo. $(A, C)$ Tumor volumes of DLD1 cell xenografts in NOD-SCID mice; $5 \times 10^{6}$ DLD1 tumor cells were injected subcutaneously. Mice were randomized into 4 groups $(\mathrm{n}=9-10)$. Mice were treated with bevacizumab (5 mg/kg/2 w) via intraperitoneal (IP) injection along with either QNZ (left) $(1 \mathrm{mg} / \mathrm{kg} / \mathrm{d}$ ) or papaverine (left) $(10 \mathrm{mg} / \mathrm{kg} / \mathrm{d})$, administered by gavage. (B,D) Representative staining for Ki-67, p-S6RP, and CD31. Statistical significance was calculated on end points using one-way ANOVA.

\section{Discussion}

Tumor cells often grow within a metabolically deprived tumor microenvironment. This implies that tumor cells need to adapt to such conditions in order to develop into macroscopic tumors. In many 
cases, tumor cells exploit endogenous protective pathways for their own advantage, including those supporting survival under metabolic stress [14,23,25-42]. Tumor cells, however, become addicted to such survival mechanisms $[6,11,17,43]$, thereby offering potential weaknesses that can be targeted. To uncover compounds targeting these adaptive mechanisms, we carried out a phenotypic drug screen in cells growing in glucose-deprivation versus normal conditions. This led to the identification of 67 compounds presenting selective toxicity towards glucose-starved tumor cells. We validated two of these drugs, papaverine and QNZ, which are both mitochondrial complex I inhibitors. Our data demonstrate that both papaverine and QNZ exhibited selective toxicity under glucose starvation, and more importantly, enhanced the efficacy of the antiangiogenic bevacizumab against tumor xenografts in vivo. Bevacizumab is an anti-VEGF inhibitor which inhibits the growth of blood vessels in colon cancer tumors [44] and is used clinically to treat colon cancer [44]. Our results thus highlight how compounds that sensitize tumors cells to glucose starvation can enhance the antitumorigenic activity of bevacizumab in vivo. This can lay the groundwork for further developing drug synergies between glucose deprivation-selective compounds and metabolic stress-inducing agents (such as antiangiogenics and 2-deoxyglucose) to improve tumor targeting.

The ability of tumor cells to survive glucose deprivation relies on profound metabolic reprogramming. This includes the blocking of anabolic processes, such as protein and fatty acid synthesis, and the activation of catabolic processes, such as fatty acid oxidation, together allowing cells to maintain redox balance and prevent energy depletion $[1,33,45]$. However, how mitochondrial activity responds to glucose-deprived conditions is still poorly understood. The induction of mitochondrial activity (i.e., oxygen consumption) in response to low-glucose conditions has been reported, but only in cells resistant to such growth conditions [9]. This suggests that an increase in mitochondrial activity may be linked to improved survival under glucose-deprived conditions. While glycolysis is less active under glucose starvation, it is possible that mitochondrial activity is enhanced to compensate and generate sufficient ATP and cofactors involved in redox reactions. Strikingly, a high proportion of the glucose-starved cell-selective compounds we identified are mitochondrial toxins (approximately $50 \%$ of the compounds). This supports the notion that tumor cells rely heavily on mitochondrial activity to survive and adapt to glucose deprivation. Therefore, employing mitochondrial toxins to selectively target tumor cells experiencing metabolic stress may be a promising therapeutic approach. Notably, a number of mitochondrial toxins have been successfully used to restrict tumor growth in vivo, such as doxorubicin [9] and metformin [46], although not in combination with metabolic stress-inducing agents.

Papaverine is a non-narcotic opiate alkaloid commonly used in the clinic for treatment of spasms [47] and erectile dysfunction [48]. Recently, papaverine was found to sensitize tumors to radiation therapy by inhibiting mitochondrial complex $\mathrm{I}$, thus reducing tumor cell respiration and promoting tumor oxygenation [49]. We identified papaverine in our HTP screen for compounds sensitizing cells to glucose starvation in culture. In vivo, papaverine significantly enhanced the activity of bevacizumab in reducing tumor growth, thus providing support to our model. Interestingly, since papaverine is regularly used in the clinic and as bevacizumab is used as a first-line treatment in colon cancer, it is conceivable that the combination of the two would be beneficial and quickly available in patients. In addition, QNZ was not only shown to act as a mitochondrial complex I inhibitor in vitro [21], but also to inhibit NF-kB in a pathway known to promote survival under glucose starvation [17]. It is, therefore, possible that NF-kB inhibition may contribute to the selective toxicity of QNZ under glucose starvation.

Finally, we found that both papaverine and QNZ selectively inhibited the mTOR pathway in glucose-starved cells, which was confirmed in vivo in combined treatment with bevacizumab. Since mTOR inhibition is required to prevent cell death in response to glucose deprivation $[12,16,50,51]$, these results may be indicative of the energy-depleted status of the cell. Indeed, by inhibiting mitochondrial activity, papaverine and QNZ may deplete mitochondrial ATP levels under glucose deprivation. Given 
that mTOR is a hub whose activity depends on ATP levels, this scenario would be expected to lead to an inhibition of the mTOR pathway, in accordance with our observations.

\section{Limitations of Our Study}

We identified compounds exhibiting selective toxicity upon glucose starvation in vitro and found that two of the identified compounds synergize with avastin in inhibiting tumor growth in vivo. The synergic effect we observed in vivo may be due to the induction of glucose starvation by avastin treatment, but it may also be caused by hypoxia triggered by this compound or by a combination of both. It also remains to be determined whether such synergic action is specific to avastin or will occur with other antiangiogenic compounds and calorie-restriction mimetics. In addition, given that glucose-starved cells are dependent on mitochondria to survive under glucose starvation and since the compounds we identified are known inhibitors of mitochondrial complex 1, it is likely that QNZ and papaverine enhance the antitumoral activity of avastin by targeting the mitochondria in vivo. However, potential other mechanisms cannot be excluded until this hypothesis is formally tested.

\section{Conclusions}

In conclusion, our HTP drug screen confirmed the mitochondrial dependence of glucose-starved tumor cells. Two of the identified compounds were validated in vivo and found to enhance the antitumor activity of the antiangiogenic compound bevacizumab, highlighting a new concept whereby drugs targeting the mitochondria may enhance the activity of avastin.

Supplementary Materials: The following are available online at http:/ / www.mdpi.com/2072-6694/11/2/156/s1, Table S1. List of compounds identified in the HTP. Table S2. Validated compounds found to selectively reduce cell viability upon glucose starvation.

Author Contributions: Conceptualization, G.L. and B.R.; Investigation, R.M., M.P., T.I., S.T., M.E., and B.R.; Supervision, M.E. and B.R.; Writing-original draft, G.L., M.E., and B.R.

Funding: This research was supported by the ISRAEL SCIENCE FOUNDATION (\#1124/15 to B.R. and \#700/16 to M.E.) and the Israeli Cancer Association (grant \#20180012 to B.R. and \#20170024 to ME). M.E. is supported by the Alon fellowship for outstanding young researchers. G.L. is supported by the Deutsche Forschungsgemeinschaft (LE 3751/2-1), the German Cancer Aid (70112624), and an intramural grant of the research commission of the Medical Faculty of the Heinrich-Heine-University, Düsseldorf. The National Institute for Biotechnology in the Negev provided support for this project.

Conflicts of Interest: The authors declare no conflict of interest.

\section{References}

1. Hay, N. Reprogramming glucose metabolism in cancer: can it be exploited for cancer therapy? Nat. Rev. Cancer 2016, 16, 1-15. [CrossRef] [PubMed]

2. Crabtree, H.G. The carbohydrate metabolism of certain pathological overgrowths. Biochem. J. 1928, 22, 1289-1298. [CrossRef] [PubMed]

3. Stine, Z.E.; Walton, Z.E.; Altman, B.J.; Hsieh, A.L.; Dang, C.V. MYC, Metabolism, and Cancer. Cancer Discov. 2015, 5, 1024-1039. [CrossRef] [PubMed]

4. Ying, H.; Kimmelman, A.C.; Lyssiotis, C.A.; Hua, S.; Chu, G.C.; Fletcher-Sananikone, E.; Locasale, J.W.; Son, J.; Zhang, H.; Coloff, J.L.; et al. Oncogenic Kras maintains pancreatic tumors through regulation of anabolic glucose metabolism. Cell 2012, 149, 656-670. [CrossRef]

5. Flavahan, W.A.; Wu, Q.; Hitomi, M.; Rahim, N.; Kim, Y.; Sloan, A.E.; Weil, R.J.; Nakano, I.; Sarkaria, J.N.; Stringer, B.W.; et al. Brain tumor initiating cells adapt to restricted nutrition through preferential glucose uptake. Nat. Neurosci. 2013, 16, 1373-1382. [CrossRef]

6. Gao, M.; Liang, J.; Lu, Y.; Guo, H.; German, P.; Bai, S.; Jonasch, E.; Yang, X.; Mills, G.B.; Ding, Z. Site-specific activation of AKT protects cells from death induced by glucose deprivation. Oncogene 2014, 33, 745-755. [CrossRef] [PubMed] 
7. Komurov, K.; Tseng, J.-T.; Muller, M.; Seviour, E.G.; Moss, T.J.; Yang, L.; Nagrath, D.; Ram, P.T. The glucose-deprivation network counteracts lapatinib-induced toxicity in resistant ErbB2-positive breast cancer cells. Mol. Syst. Biol. 2012, 8, 1-10. [CrossRef] [PubMed]

8. Masui, K.; Tanaka, K.; Akhavan, D.; Babic, I.; Gini, B.; Matsutani, T.; Iwanami, A.; Liu, F.; Villa, G.R.; Gu, Y.; et al. MTOR complex 2 controls glycolytic metabolism in glioblastoma through FoxO acetylation and upregulation of c-Myc. Cell Metab. 2013, 18, 726-739. [CrossRef]

9. Birsoy, K.; Possemato, R.; Lorbeer, F.K.; Bayraktar, E.C.; Thiru, P.; Yucel, B.; Wang, T.; Chen, W.W.; Clish, C.B.; Sabatini, D.M. Metabolic determinants of cancer cell sensitivity to glucose limitation and biguanides. Nature 2014, 508, 108-112. [CrossRef]

10. Hirayama, A.; Kami, K.; Sugimoto, M.; Sugawara, M.; Toki, N.; Onozuka, H.; Kinoshita, T.; Saito, N.; Ochiai, A.; Tomita, M.; et al. Quantitative metabolome profiling of colon and stomach cancer microenvironment by capillary electrophoresis time-of-flight mass spectrometry. Cancer Res. 2009, 69, 4918-4925. [CrossRef]

11. Saito, S.; Furuno, A.; Sakurai, J.; Sakamoto, A.; Park, H.-R.; Shin-Ya, K.; Tsuruo, T.; Tomida, A. Chemical genomics identifies the unfolded protein response as a target for selective cancer cell killing during glucose deprivation. Cancer Res. 2009, 69, 4225-4234. [CrossRef] [PubMed]

12. Choo, A.Y.; Kim, S.G.; Vander Heiden, M.G.; Mahoney, S.J.; Vu, H.; Yoon, S.O.; Cantley, L.C.; Blenis, J. Glucose Addiction of TSC Null Cells Is Caused by Failed mTORC1-Dependent Balancing of Metabolic Demand with Supply. Mol. Cell 2010, 38, 487-499. [CrossRef] [PubMed]

13. Inoki, K.; Ouyang, H.; Zhu, T.; Lindvall, C.; Wang, Y.; Zhang, X.; Yang, Q.; Bennett, C.; Harada, Y.; Stankunas, K.; et al. TSC2 Integrates Wnt and Energy Signals via a Coordinated Phosphorylation by AMPK and GSK3 to Regulate Cell Growth. Cell 2006, 126, 955-968. [CrossRef] [PubMed]

14. Pusapati, R.V.; Daemen, A.; Wilson, C.; Sandoval, W.; Gao, M.; Haley, B.; Baudy, A.R.; Hatzivassiliou, G.; Evangelista, M.; Settleman, J. MTORC1-Dependent Metabolic Reprogramming Underlies Escape from Glycolysis Addiction in Cancer Cells. Cancer Cell 2016, 29, 548-562. [CrossRef] [PubMed]

15. Saxton, R.A.; Sabatini, D.M. mTOR Signaling in Growth, Metabolism, and Disease. Cell 2017, 168, 960-976. [CrossRef] [PubMed]

16. Inoki, K.; Zhu, T.; Guan, K.-L. TSC2 mediates cellular energy response to control cell growth and survival. Cell 2003, 115, 577-590. [CrossRef]

17. Mauro, C.; Leow, S.C.; Anso, E.; Rocha, S.; Thotakura, A.K.; Tornatore, L.; Moretti, M.; De Smaele, E.; Beg, A.A.; Tergaonkar, V.; et al. NF-KB controls energy homeostasis and metabolic adaptation by upregulating mitochondrial respiration. Nat. Cell Biol. 2011, 13, 1272-1279. [CrossRef] [PubMed]

18. Cairns, R.A.; Harris, I.S.; Mak, T.W. Regulation of cancer cell metabolism. Nat. Rev. Cancer 2011, 11, 85-95. [CrossRef]

19. Weinberg, S.E.; Chandel, N.S. Targeting mitochondria metabolism for cancer therapy. Nat. Publ. Gr. 2015, 11, 9-15. [CrossRef]

20. Vyas, S.; Zaganjor, E.; Haigis, M.C. Mitochondria and Cancer. Cell 2016, 166, 555-566. [CrossRef]

21. Krishnathas, R.; Bonke, E.; Dröse, S.; Zickermann, V.; Nasiri, H.R. Identification of 4-N-[2-(4-phenoxyphenyl) ethyl]quinazoline-4,6-diamine as a novel, highly potent and specific inhibitor of mitochondrial complex I. Medchemcomm 2017, 8, 657-661. [CrossRef] [PubMed]

22. Morikawa, N.; Nakagawa-Hattori, Y.; Mizuno, Y. Effect of dopamine, dimethoxyphenylethylamine, papaverine, and related compounds on mitochondrial respiration and complex I activity. J. Neurochem. 1996, 66, 1174-1181. [CrossRef]

23. Leprivier, G.; Remke, M.; Rotblat, B.; Dubuc, A.; Mateo, A.-R.F.; Kool, M.; Agnihotri, S.; El-Naggar, A.; Yu, B.; Somasekharan, S.P.; et al. The eEF2 kinase confers resistance to nutrient deprivation by blocking translation elongation. Cell 2013, 153, 1064-1079. [CrossRef] [PubMed]

24. Musa, J.; Orth, M.F.; Dallmayer, M.; Baldauf, M.; Pardo, C.; Rotblat, B.; Kirchner, T.; Leprivier, G.; Grünewald, T.G.P. Eukaryotic initiation factor 4E-binding protein 1 (4E-BP1): A master regulator of mRNA translation involved in tumorigenesis. Oncogene 2016, 1, 1-14. [CrossRef] [PubMed]

25. Lin, A.; Li, C.; Xing, Z.; Hu, Q.; Liang, K.; Han, L.; Wang, C.; Hawke, D.H.; Wang, S.; Zhang, Y.; et al. The LINK-A lncRNA activates normoxic HIF1 $\alpha$ signalling in triple-negative breast cancer. Nat. Cell Biol. 2016, 18, 1-12. [CrossRef] [PubMed] 
26. Rotblat, B.; Grunewald, T.G.P.; Leprivier, G.; Melino, G.; Knight, R.A. Anti-oxidative stress response genes: bioinformatic analysis of their expression and relevance in multiple cancers. Oncotarget 2013, 4, 2577-2590. [CrossRef] [PubMed]

27. Lin, H.; Patel, S.; Affleck, V.S.; Wilson, I.; Turnbull, D.M.; Joshi, A.R.; Maxwell, R.; Stoll, E.A. Fatty acid oxidation is required for the respiration and proliferation of malignant glioma cells. Neuro. Oncol. 2017, 1, 43-54. [CrossRef]

28. Dey, P.; Baddour, J.; Muller, F.; Wu, C.C.; Wang, H.; Liao, W.-T.; Lan, Z.; Chen, A.; Gutschner, T.; Kang, Y.; et al. Genomic deletion of malic enzyme 2 confers collateral lethality in pancreatic cancer. Nature 2017, 542, 119-123. [CrossRef]

29. Cetinbas, N.; Daugaard, M.; Mullen, A.R.R.; Hajee, S.; Rotblat, B.; Lopez, A.; Li, A.; DeBerardinis, R.J.J.; Sorensen, P.H.H. Loss of the tumor suppressor Hace1 leads to ROS-dependent glutamine addiction. Oncogene 2014, 34, 1-6. [CrossRef]

30. Guan, B.J.; van Hoef, V.; Jobava, R.; Elroy-Stein, O.; Valasek, L.S.; Cargnello, M.; Gao, X.H.; Krokowski, D.; Merrick, W.C.; Kimball, S.R.; et al. A Unique ISR Program Determines Cellular Responses to Chronic Stress. Mol. Cell 2017, 68, 885-900.e6. [CrossRef]

31. Boroughs, L.K.; DeBerardinis, R.J. Metabolic pathways promoting cancer cell survival and growth. Nat. Cell Biol. 2015, 17, 351-359. [CrossRef] [PubMed]

32. Ibrahim-Hashim, A.; Robertson-Tessi, M.; Enriquez-Navas, P.M.; Damaghi, M.; Balagurunathan, Y.; Wojtkowiak, J.W.; Russell, S.; Yoonseok, K.; Lloyd, M.C.; Bui, M.M.; et al. Defining cancer subpopulations by adaptive strategies rather than molecular properties provides novel insights into intratumoral evolution. Cancer Res. 2017, 77, 2242-2254. [CrossRef] [PubMed]

33. Jeon, S.-M.; Chandel, N.S.; Hay, N. AMPK regulates NADPH homeostasis to promote tumour cell survival during energy stress. Nature 2012, 485, 661-665. [CrossRef] [PubMed]

34. Harris, I.S.; Treloar, A.E.; Inoue, S.; Sasaki, M.; Gorrini, C.; Lee, K.C.; Yung, K.Y.; Brenner, D.; Knobbe-Thomsen, C.B.; Cox, M.A.; et al. Glutathione and Thioredoxin Antioxidant Pathways Synergize to Drive Cancer Initiation and Progression. Cancer Cell 2015, 27, 1-12. [CrossRef]

35. Mai, W.X.; Gosa, L.; Daniels, V.W.; Ta, L.; Tsang, J.E.; Higgins, B.; Gilmore, W.B.; Bayley, N.A.; Harati, M.D.; Lee, J.T.; et al. Cytoplasmic p53 couples oncogene-driven glucose metabolism to apoptosis and is a therapeutic target in glioblastoma. Nat. Med. 2017, 23, 1342-1351. [CrossRef] [PubMed]

36. Guri, Y.; Colombi, M.; Dazert, E.; Hindupur, S.K.; Roszik, J.; Moes, S.; Jenoe, P.; Heim, M.H.; Riezman, I.; Riezman, H.; et al. mTORC2 Promotes Tumorigenesis via Lipid Synthesis. Cancer Cell 2017, 32, 807-823.e12. [CrossRef] [PubMed]

37. Griss, T.; Vincent, E.E.; Egnatchik, R.; Chen, J.; Ma, E.H.; Faubert, B.; Viollet, B.; DeBerardinis, R.J.; Jones, R.G.; Andrzejewski, S.; et al. Metformin Antagonizes Cancer Cell Proliferation by Suppressing Mitochondrial-Dependent Biosynthesis. PLoS Biol. 2015, 13, e1002309. [CrossRef] [PubMed]

38. Ng, T.L.; Leprivier, G.; Robertson, M.D.; Chow, C.; Martin, M.J.; Laderoute, K.R.; Davicioni, E.; Triche, T.J.; Sorensen, P.H.B. The AMPK stress response pathway mediates anoikis resistance through inhibition of mTOR and suppression of protein synthesis. Cell Death Differ. 2012, 19, 501-510. [CrossRef]

39. Leprivier, G.; Rotblat, B.; Khan, D.; Jan, E.; Sorensen, P.H. Stress-mediated translational control in cancer cells. Biochim. Biophys. Acta Gene Regul. Mech. 2014, 1849, 845-860. [CrossRef]

40. Robichaud, N.; Sonenberg, N. Translational control and the cancer cell response to stress. Curr. Opin. Cell Biol. 2017, 45, 102-109. [CrossRef]

41. Ilagan, E.; Manning, B.D. Emerging Role of mTOR in the Response to Cancer Therapeutics. Trends Cancer 2016, 2, 241-251. [CrossRef] [PubMed]

42. Vincent, E.E.; Sergushichev, A.; Griss, T.; Gingras, M.; Samborska, B.; Ntimbane, T.; Coelho, P.P.; Blagih, J.; Raissi, T.C.; Choinière, L.; et al. Mitochondrial Phosphoenolpyruvate Carboxykinase Regulates Metabolic Adaptation and Enables Glucose-Independent Tumor Growth. Mol. Cell 2015, 60, 195-207. [CrossRef] [PubMed]

43. Dan, H.C.; Cooper, M.J.; Cogswell, P.C.; Duncan, J.A.; Ting, J.P.-Y.; Baldwin, A.S. Akt-dependent regulation of NF-\{kappa\}B is controlled by mTOR and Raptor in association with IKK. Genes Dev. 2008, 22, 1490-1500. [CrossRef] 
44. Hurwitz, H.; Fehrenbacher, L.; Novotny, W.; Cartwright, T.; Hainsworth, J.; Heim, W.; Berlin, J.; Baron, A.; Griffing, S.; Holmgren, E.; et al. Bevacizumab plus Irinotecan, Fluorouracil, and Leucovorin for Metastatic Colorectal Cancer. N. Engl. J. Med. 2004, 350, 2335-2342. [CrossRef] [PubMed]

45. Pavlova, N.N.; Thompson, C.B. The Emerging Hallmarks of Cancer Metabolism. Cell Metab. 2016, $23,27-47$. [CrossRef] [PubMed]

46. Wheaton, W.W.; Weinberg, S.E.; Hamanaka, R.B.; Soberanes, S.; Sullivan, L.B.; Anso, E.; Glasauer, A.; Dufour, E.; Mutlu, G.M.; Budigner, G.S.; et al. Metformin inhibits mitochondrial complex I of cancer cells to reduce tumorigenesis. eLife 2014, 3, e02242. [CrossRef]

47. Kassell, N.F.; Helm, G.; Simmons, N.; Phillips, C.D.; Cail, W.S. Treatment of cerebral vasospasm with intra-arterial papaverine. J. Neurosurg. 1992, 77, 848-852. [CrossRef]

48. Virag, R. Intracavernous injection of papaverine for erectile failure. J. Urol. 2002, 167, 1196. [CrossRef]

49. Benej, M.; Hong, X.; Vibhute, S.; Scott, S.; Wu, J.; Graves, E.; Le, Q.-T.; Koong, A.C.; Giaccia, A.J.; Yu, B.; et al. Papaverine and its derivatives radiosensitize solid tumors by inhibiting mitochondrial metabolism. Proc. Natl. Acad. Sci. USA 2018, 115, 10756-10761. [CrossRef]

50. Palm, W.; Park, Y.; Wright, K.; Pavlova, N.N.; Tuveson, D.A.; Thompson, C.B. The Utilization of Extracellular Proteins as Nutrients Is Suppressed by mTORC1. Cell 2015, 162, 259-270. [CrossRef]

51. Ma, X.M.; Blenis, J. Molecular mechanisms of mTOR-mediated translational control. Nat. Rev. Mol. Cell Biol. 2009, 10, 307-318. [CrossRef] [PubMed]

(C) 2019 by the authors. Licensee MDPI, Basel, Switzerland. This article is an open access article distributed under the terms and conditions of the Creative Commons Attribution (CC BY) license (http:/ / creativecommons.org/licenses/by/4.0/). 